\title{
Health related quality of life of patients undergoing oral anticoagulation therapy
}

\author{
Inaiara Scalçone Almeida Corbi ${ }^{1}$ \\ Rosana Aparecida Spadoti Dantas ${ }^{2}$ \\ Flávia Martinelli Pelegrino ${ }^{3}$ \\ Ariana Rodrigues da Silva Carvalho ${ }^{4}$
}

This is a descriptive cross-sectional study, which aimed to analyze the health related quality of life (HRQOL) and its relationship with gender, age, duration and indication for the use of oral anticoagulants. A total of 178 patients were interviewed and the HRQoL was assessed through eight domains of the SF-36. The descriptive statistics used were, the Student's $t$, ANOVA and Tukey's tests for the comparison of the means between the groups. The indication for use was predominantly the metallic prosthetic heart valve $(50 \%)$ with warfarin the most widely prescribed anticoagulant $(83.3 \%)$. The means of the domains of the SF36 ranged from 82 (Social aspects) to 54.8 (Physical aspects). Women, elderly, patients diagnosed with atrial fibrillation and with less than one year of medication use, presented a worse HRQoL evaluation. The results obtained can guide nursing actions, in that they indicate possible associations between the HRQoL and the sociodemographic and clinical variables of the patients.

Descriptors: Quality of Life; Anticoagulants; Ambulatory Care.

\footnotetext{
${ }^{1}$ RN, M.Sc. in nursing. E-mail: inaenf@yahoo.com.br.

${ }^{3} \mathrm{RN}$, M.Sc. in nursing. E-mail: flavia-martinelli@bol.com.br.

${ }^{4}$ RN, Ph.D. in Health Sciences. E-mail: mauroari2@hotmail.com.

Corresponding Author:

2 RN, Ph.D. in nursing, Associate Professor, Escola de Enfermagem de Ribeirão Preto, Universidade de São Paulo, WHO Collaborating Centre for Nursing Research Development, SP, Brazil. E-mail: rsdantas@eerp.usp.br. 


\section{Qualidade de vida relacionada à saúde de pacientes em uso de anticoagulação oral}

Trata-se de estudo descritivo, tipo corte transversal, que teve como objetivo analisar a qualidade de vida relacionada à saúde (QVRS) e sua relação com sexo, idade, tempo e indicação para o uso de anticoagulantes orais. Foram entrevistados 178 pacientes e a QVRS foi avaliada pelos oito domínios do SF-36. Usaram-se estatística descritiva, testes t de Student, ANOVA e Tukey para comparação das médias entre os grupos. A indicação para o uso foi predominantemente a prótese cardíaca metálica (50\%) e a varfarina o anticoagulante mais prescrito $(83,3 \%)$. As médias dos domínios do SF-36 variaram de 82 (aspectos sociais) a 54,8 (aspectos físicos). Mulheres, idosos e pacientes, com diagnóstico de fibrilação atrial e menos de um ano de uso do medicamento, apresentaram pior avaliação da QVRS. Os resultados obtidos podem nortear ações de enfermagem, na medida em que indica possíveis associações entre a QVRS e variáveis sociodemográficas e clínicas dos pacientes.

Descritores: Qualidade de Vida; Anticoagulantes; Assistência Ambulatorial.

\section{Calidad de vida relacionada a la salud de pacientes que usan anticoagulación oral}

Se trata de un estudio descriptivo, de tipo corte transversal, que tuvo como objetivo analizar la calidad de vida relacionada a la salud (CVRS) y su relación con sexo, edad, tiempo e indicación de uso de anticoagulantes orales. Fueron entrevistados 178 pacientes y la CVRS fue evaluada por los ocho dominios del SF-36. Fue utilizada estadística descriptiva, las pruebas: t Student, ANOVA y Tukey, para comparación de los promedios entre los grupos. La indicación para el uso fue predominantemente la prótesis cardíaca metálica ( $50 \%$ ) y la warfarina el anticoagulante más prescrito $(83,3 \%)$. Los promedios de los dominios del SF-36 variaron de 82 (Aspectos sociales) a 54,8 (Aspectos físicos). Mujeres, ancianos, y pacientes con diagnóstico de fibrilación atrial y con menos de un año de uso del medicamento, presentaron peor evaluación de la CVRS. Los resultados obtenidos pueden orientar acciones de enfermería, en la medida en que indican posibles asociaciones entre la CVRS y las variables sociodemográficas y clínicas de los pacientes.

Descriptores: Calidad de Vida; Anticoagulantes; Atención Ambulatoria.

\section{Introduction}

Some cardiovascular diseases precipitate an unwanted blood coagulation action requiring the use of oral anticoagulants (OACs). The clinical applications of OACs have been evidenced through studies of various conditions, such as atrial fibrillation, venous thromboembolism, patients with prosthetic heart valves, congestive heart failure, myocardial infarction and other special situations $^{(1)}$. The therapeutic action of the OAC can be influenced by numerous conditions that alter its absorption and metabolism. The intake of foods rich in fats and vitamin $\mathrm{K}$, drugs containing acetylsalicylic acid and alcohol can be cited as examples. The changes in the desired levels of blood anticoagulation can cause hemorrhagic or thromboembolic events, harming the patient $^{(1)}$. For the evaluation of the anticoagulation levels, laboratory control is accomplished through frequent blood sampling in order to obtain the International Normalized Ratio (INR) ${ }^{(2)}$. Currently, for most patients, the maintenance of moderate intensity anticoagulation is recommended, i.e. with INR values ranging from 2 to 3. This interval may vary according to the indications for the oral anticoagulant ${ }^{(3-4)}$. 
The use of OACs requires some care in order to control the desirable levels of blood coagulation and to prevent hemorrhagic and thromboembolic complications. Such care can lead to changes in the lifestyle of users since this involves changes in the dietary habits, the use of alcohol and the performance of physical activity ${ }^{(5-6)}$, as well as the overload caused by new tasks related to the use of medication, such as the habit of daily ingestion of the medication and the need for frequent visits to health services for monitoring of the anticoagulation range, and the fear of complications such as bleeding and thrombus formation(7). All these changes caused by the use of the drug may impair the quality of life of the patient. The term health related quality of life (HRQoL) has been used when the concern of researchers is to investigate the influence of the disease and treatment on the quality of life of the individual(8). This narrower concept has been used to avoid ambiguity between the definition of quality of life in the common sense and that used in clinical and medical trials, which is the focus of this study.

The evaluation of patients regarding the effects of the use of oral anticoagulants also deserves investigation. A study published in the early $1990 s^{(5)}$ has already pointed out the negative effects of oral anticoagulants in the evaluation of the health status of the patients, when related to the presence of collateral effects of the medication. The fear of the occurrence of bleeding also caused increased anxiety in those individuals who had experienced this complication of the treatment. In oral anticoagulation therapy, as in other therapies for chronic conditions, the acceptance of the individuals, with reference to changing habits and behaviors, is necessary to be able to prevent later complications. Therefore, the success of each therapy depends on how each individual perceives its benefits(5). Positive perceptions are related to a better control of the oral anticoagulation therapy and better $\mathrm{HRQOL}^{(6)}$, with the reduction of the number of oral anticoagulation therapy complications associated with improved HRQoL ${ }^{(1)}$.

In order to study the HRQoL of the users of oral anticoagulants, authors have used different types of instruments. Some authors used a measurement of HRQoL obtained through the generic instrument the Medical Outcomes Survey 36-item Short Form (SF-36) $(6,9-12)$ and found that the more impaired HRQoL domains were Physical aspects and Vitality ${ }^{(6,10)}$, Pain(11), Physical functioning and General health status( ${ }^{(6)}$. In Brazil, in a study that followed patients for the first six months of oral anticoagulation therapy, the author found that the mean values of the SF-36 domains ranged from 32.4 (Physical aspects) to 82.7 (Social aspects) at the beginning of the treatment. Six months after the beginning of the OAC therapy, the means of the domains were higher and ranged from 72.1 (Vitality) to 90.7 (Social aspects)(12). The measurement of HRQoL obtained by the SF-36 was also used in a study that evaluated the psychometric properties of an adherence instrument, aimed at patients using $\mathrm{OACs}^{(13)}$. In a literature review regarding specific instruments available to evaluate the HRQoL of patients using OACs, the authors identified only seven instruments(14). In Brazil, one of these instruments, the Duke Anticoagulation Satisfaction Scale(11), was recently validated ${ }^{(15)}$, and its use permitted the finding of improvements in the HRQoL six months after starting treatment, especially in the Psychological impact domain (12).

The HRQoL of patients using OAC and the quality of the oral anticoagulation therapy have been associated with sociodemographic (age and gender) and clinical variables (indication for and the duration of the oral anticoagulation therapy $)^{(6,12,16)}$. In the clinical practice of nurses, they are increasingly faced with patients using OAC under their care. A better understanding of the profile of these individuals and the impact of this therapy on the HRQoL will contribute to better planning of this care. Considering the scarcity of published Brazilian studies that investigate the HRQoL of patients receiving oral anticoagulation ${ }^{(12)}$, this study proposed to answer the following questions:

- What is the health related quality of life of patients using oral anticoagulants, in outpatient monitoring?

- Is there a difference between the health related quality of life of patients using oral anticoagulants according to the variables gender and age?

- Is there a difference between the health related quality of life of patients using oral anticoagulants according to the variables indication for the use of oral anticoagulants and duration of the therapy?

Given the above, this study aimed to analyze the HRQoL and its relationship with gender, age, duration and indication for use of oral anticoagulants.

\section{Method}

Design, population and ethical aspects: This is a descriptive cross-sectional study performed in an oral anticoagulation outpatient clinic of a teaching hospital in the State of São Paulo. The sample was non-probabilistic and consisted of 178 patients who attended the service 
for evaluation of blood coagulation, verified by INR, in the period from March to August 2008 and that met the following inclusion criteria: to be 18 years of age or more and to be treated with OACs for at least two months. The exclusion criteria were: to have cognitive or verbal difficulty to respond to the instruments of the study, or to have a reported diagnosis of psychiatric disorders in the medical record.

The project was approved by the Research Ethics Committee of the institution where the study was conducted under process No. 6738/2007. All participants signed the Terms of Free Prior Informed Consent, in duplicate, a copy of which was kept by the researchers and the other by the participant, in accordance with regulations of the National Health Council It was explained to each subject that their privacy and anonymity would be guaranteed.

The sociodemographic data collected were: age, gender, marital status, schooling, occupation and monthly family income. In addition, data were included, such as: the type of OAC, the indication for its use, duration of the treatment, weekly dose of the OAC, the last INR value, associated diseases recorded in the medical records, and other medication in use. The evaluation of the HRQoL was obtained through the instrument Medical Outcomes Survey 36 -Item Short-Form (SF-36) ${ }^{(17)}$, in its validated Portuguese version ${ }^{(18)}$. This instrument consists of 36 items, of which 35 items are grouped into eight domains: Functional capacity (10 items), Physical aspects (four), Pain (two), General health status (five), Vitality (four), Social aspects (two), Emotional aspects (three), Mental health (five) and one more question of the comparative evaluation between the current evaluation of the health condition of the individual and the condition a year ago. Each domain presents values on a scale of zero to 100 , with higher values indicating better perceived health status or HRQoL ${ }^{(18)}$. In the present study, the Cronbach's alpha values obtained ranged from 0.97 (Emotional aspects) to 0.69 (Social aspects), indicating good internal consistency of the items in the group studied.

The data were analyzed using the program Statistical Package for the Social Sciences (SPSS) version 15.0. Descriptive analysis was performed for the sociodemographic and clinical data and for the scores of the SF-36. The Student's t test was used to verify the differences between the means of the HRQoL measurements, according to gender. To compare the means of HRQoL according to age (less than 40 years, between 40 and 59 years, and 60 years or older), indications for the oral anticoagulation therapy (metallic prosthetic heart valve, atrial fibrillation, and other indications), and duration of medication use (up to 1 year, 1 to 3 years, 3 to 5 years, 5 to 10 years, and over 10 years) Analysis of Variance (ANOVA) and Tukey's test were performed. The level of significance adopted was 0.05 .

\section{Results}

Regarding the sociodemographic and clinical characteristics of the 178 subjects studied, the majority were female $(116 ; 65.2 \%)$, married (116; $65.2 \%)$, retired $(65 ; 36.9 \%)$, with mean age of 55.6 years (ranging from 24.8 to 86.1 ) and with complete elementary education (126; 70.8\%). Warfarin sodium was the most prescribed anticoagulant (83.1\%), with an mean dose of $33.6 \mathrm{mg} /$ week, with the indication for oral anticoagulation predominantly for individuals using metallic prosthetic heart valves (50.6\%), followed by atrial fibrillation sufferers $(33.1 \%)$. The mean duration of use of the OAC was seven years, with 2.4 as the mean value of the last INR. With regard to the presence of other comorbidities, it was found that the most prevalent were Arterial Hypertension (91; 51.1\%), Arrhythmias $(85 ; 47.8 \%)$ and Coronary Artery Disease $(77 ; 43.3 \%)$, with the prescription of antihypertensive drugs (116; $65.2 \%$ ) and diuretics (99; 55.6\%) associated with the use of OACs.

Regarding the evaluation of the HRQoL a better evaluation was obtained for Social aspects $(\bar{x}=82$, $\mathrm{SD}=26.6$ ) and worse for Physical aspects ( $x=54.8$, $\mathrm{SD}=47.8)$. The other six domains of the SF-36 varied between 66.5 (Mental health) and 62.9 (Emotional aspects). To evaluate the presence of differences in the HRQoL according to age, the subjects were separated into three age groups: less than 40 years $(n=24)$, between 40 and 59 years $(n=83)$ and 60 years or older $(n=71)$. Statistically significant differences were found between the groups in the domains Physical functioning $(p=0.012)$ and Pain $(p=0.024)$ (Table 1$)$. The comparison of multiple means using Tukey's test indicated that for the Physical functioning domain, the differences were statistically significant between the patients in the age group less than 40 years $(\bar{x}=77.7)$ and those of 40 to 59 years $(x=61.5, p=0.028$ ) and the patients of less than 40 years and those 60 years or $\operatorname{older}(\bar{x}=$ $60.2, p=0.018)$. Regarding the Pain domain, there was a statistically significant difference only when comparing the group 60 years or older $(\bar{x}=66.3)$ with the group between 40 and 59 years $(\bar{x}=54.6)(p=0.043)$. 
Table 1 - Comparison of the means of the domains of the SF-36, according to the age of the subjects

\begin{tabular}{|c|c|c|c|c|}
\hline \multirow{2}{*}{ Domains of the SF-36 } & Less than 40 years & Between 40 and 59 years & 60 years or older & \multirow{2}{*}{$\mathbf{p}^{*}$} \\
\hline & Mean (sd) & Mean (sd) & Mean (sd) & \\
\hline Physical functioning & $77.7(20.3)$ & $61.5(30.3)$ & $60.2(24.4)$ & 0.012 \\
\hline Pain & $66.0(31.0)$ & $54.6(29.5)$ & $66.3(29.7)$ & 0.024 \\
\hline Vitality & $65.2(27.0)$ & $62.4(24.9)$ & $70.2(23.3)$ & 0.11 \\
\hline Mental health & $63.3(28.2)$ & $64.1(25.4)$ & $70.2(23.6)$ & 0.30 \\
\hline General Health Status & $63.7(27.2)$ & $70.4(24.0)$ & $69.2(24.7)$ & 0.56 \\
\hline Physical aspects & $58.3(48.1)$ & $57.2(47.4)$ & $50.7(48.5)$ & 0.61 \\
\hline Social Aspects & $76.0(32.9)$ & $81.5(26.7)$ & $84.7(24.0)$ & 0.67 \\
\hline Emotional aspects & $58.3(50.4)$ & $61.4(48.4)$ & $66.2(47.3)$ & 0.71 \\
\hline
\end{tabular}

* ANOVA test

When comparing HRQoL according to the gender of the subjects, statistically significant differences were observed in the domains Mental health $(p=0.008)$ and
Pain $(p=0.019)$, the best evaluation being for males, with mean values of 74 and 68 respectively (Table 2 ).

Table 2 - Comparison of the means of the domains of the SF-36, according to the gender of the subjects

\begin{tabular}{lll}
\hline \multicolumn{1}{c}{ Domains of the SF-36 } & Women & Men \\
\cline { 2 - 3 } & Mean (sd) & Mean (sd) \\
\hline Mental health & $62.4(27.0)$ & $74.0(19.2)$ \\
Pain & $57.0(30.3)$ & $68.0(28.8)$ \\
Emotional aspects & $58.5(48.9)$ & $70.9(45.7)$ \\
Physical functioning & $61.7(27.7)$ & $67.0(26.4)$ \\
Vitality & $63.7(26.5)$ & $70.0(20.4)$ \\
Social Aspects & $80.5(28.4)$ & $84.9(22.9)$ \\
Physical aspects & $53.3(48.3)$ & $57.7(47.2)$ \\
General Health Status & $69.5(25.1)$ & 0.008 \\
\hline
\end{tabular}

* Student's t test.

The HRQoL of the participants was evaluated considering the indication for the oral anticoagulation therapy, grouped into three categories: metallic prosthetic heart valve $(n=90)$, atrial fibrillation $(n=59)$ and other indications $(n=29)$. Statistically significant differences were found between the individuals, with regard to the domains Physical aspects $(p=0.040)$ and Physical functioning $(p=0.030)$ (Table 3$)$. Tukey's test indicated that for the Physical functioning domain, the differences were statistically significant between the patients with metallic prosthetic heart valves ( $\bar{x}=$ 68.3) and those with the indication due to the presence of atrial fibrillation $(\bar{x}=56.6, p=0.028)$. Regarding the Physical aspects domain, there were statistically significant differences between patients with metallic prosthetic heart valves $(\bar{x}=64.2)$ and those with atrial fibrillation $(\bar{x}=46.1, p=0.04)$ and those with other indications ( $x=43.5, p=0.048)$.

Table 3 - Comparison of the means of the domains of the SF-36, according to clinical indication for oral anticoagulant use

\begin{tabular}{lcccc}
\hline \multirow{2}{*}{ Domains of the SF-36 } & Metallic prosthetic heart valve & Atrial fibrillation & Other indications \\
\cline { 2 - 4 } & $\begin{array}{c}\text { Mean } \mathbf{( s d )} \\
\mathbf{n = 9 0}\end{array}$ & $\begin{array}{c}\text { Mean } \mathbf{( s d )} \\
\mathbf{n = 5 9}\end{array}$ & $\begin{array}{c}\text { Mean } \mathbf{( s d )} \\
\mathbf{n = 2 9}\end{array}$ \\
\hline Physical functioning & $68.3(25.9)$ & $56.6(27.8)$ & $60.8(28.2)$ & 0.030 \\
Physical aspects & $64.2(45.6)$ & $46.1(48.2)$ & $43.1(49.5)$ & 0.040 \\
Pain & $60.8(32.0)$ & $57.3(29.0)$ & $67.7(26.3)$ & 0.31 \\
Vitality & $67.3(24.8)$ & $63.6(24.4)$ & $66.0(25.5)$ & 0.56 \\
Social Aspects & $83.9(24.9)$ & $80.7(27.7)$ & $78.9(29.9)$ & 0.58 \\
Mental health & $68.2(23.8)$ & $66.2(26.1)$ & $61.6(27.5)$ & 0.59 \\
General health status & $70.9(22.7)$ & $67.4(26.7)$ & $66.2(26.7)$ & 0.62 \\
Emotional aspects & $62.6(47.9)$ & $62.0(48.9)$ & $65.5(48.4)$ & 0.94 \\
\hline
\end{tabular}

* ANOVA test 
Regarding the differences in HRQOL according to the duration of medication use, the subjects were grouped into five categories: up to one year $(n=23)$, one to three years $(n=37)$, three to five years $(n=25)$, five to ten years $(n=50)$ and over ten years $(n=43)$. There were statistically significant differences between the groups in the domains Physical functioning $(p=0.000)$ and General health status $(p=0.023)$ (Table 4$)$. The use of Tukey's test showed that for the Physical functioning domain, the differences were statistically significant between the patients with over 10 years use of OAC $(\bar{x}=77.8)$ and those with up to one year of use $(\bar{x}=51.9, p=0.002)$ and with patients with three to five years of use $(\bar{x}=64.0$, $p=0.000$ ). Regarding the General health status domain, there were statistically significant differences between the patients with over ten years of use $(\bar{x}=77.8)$ and those with up to one year ( $x=57.1, p=0.023)$.

Table 4 - Comparison of the means of the domains of the SF-36, according to the duration of the use of oral anticoagulants of the subjects

\begin{tabular}{|c|c|c|c|c|c|c|}
\hline \multirow{2}{*}{$\begin{array}{l}\text { Domains of the } \\
\text { SF-36 }\end{array}$} & Up to 1 year & 1 to 3 years & 3 to 5 years & 5 to 10 years & Over 10 years & \multirow{2}{*}{$\mathbf{p}^{*}$} \\
\hline & Mean (sd) & Mean (sd) & Mean (sd) & Mean (sd) & Mean (sd) & \\
\hline Physical functioning & $51.9(29.5)$ & $64.4(28.2)$ & $64.0(26.2)$ & $54.5(27.7)$ & $77.8(18.5)$ & 0.000 \\
\hline General health status & $57.1(28.6)$ & $67.70(24.9)$ & $74.9(22.3)$ & $66.3(24.6)$ & $76.2(21.5)$ & 0.023 \\
\hline Physical aspects & $43.4(48.4)$ & $51.4(49.9)$ & $43.0(48.7)$ & $52.0(48.1)$ & $73.8(40.8)$ & 0.066 \\
\hline Vitality & $59.8(31.9)$ & $63.5(22.5)$ & $64.6(25.9)$ & $64.0(24.2)$ & $74.2(20.8)$ & 0.16 \\
\hline Social aspects & $69.5(35.7)$ & $78.7(29.4)$ & $88.5(17.3)$ & $81.2(27.0)$ & $88.7(19.6)$ & 0.19 \\
\hline Mental health & $56.5(31.0)$ & $63.9(23.8)$ & $67.0(23.3)$ & $67.6(24.5)$ & $72.4(23.8)$ & 0.21 \\
\hline Emotional aspects & $52.1(51.0)$ & $55.5(50.4)$ & $69.3(46.0)$ & $60.0(48.5)$ & $74.4(44.1)$ & 0.27 \\
\hline Pain & $58.2(28.6)$ & $58.7(27.1)$ & $58.2(33.0)$ & $60.2(31.7)$ & $66.2(29.7)$ & 0.75 \\
\hline
\end{tabular}

* ANOVA test

\section{Discussion}

The present study verified a greater participation of women using oral anticoagulants, a result similar to that found by other investigators $(6,12,16)$, however, in other studies, researchers have mainly evaluated males ${ }^{(5,11,15,19-20)}$. The group was composed of subjects of various ages, with $40 \%$ over 60 years of age. Similar results were found in other studies(16,19-22). It should be noted that the site in which the study was conducted is a tertiary level public hospital, characterized by its care, teaching and research activities. In this hospital, the majority of patients are attended in the Brazilian National Health System (SUS), being a reference for various specialties, including outpatient oral anticoagulation therapy, serving this region of São Paulo State. Thus, this data would justify the majority of the individuals having low schooling levels (mean 4.6 years of formal study). Among the studies reviewed, few refer to this data in the characterization of their participants, however, in those that have included such information, it was found that the participants presented higher education levels than the participants of this study ${ }^{(6,11,16)}$. The two main indications for oral anticoagulant use among the study subjects were the use of metallic prosthetic heart valves (50.6\%) and the presence of atrial fibrillation (33.1\%), with these indications also prevalent in other populations investigated(6,12,20). Other studies have found the prevalence of various indications, including: as a result of acute myocardial infarction ${ }^{(11)}$ and the presence of a pacemaker(10). These indications were also present in this study, however, due to the low frequency observed, were grouped under "other indications". Warfarin was the most prescribed oral anticoagulant among the participants, corroborating the literature data(10,22).

In the present study the investigation was undertaken of the health related quality of life of patients using oral anticoagulants, which is justified by the clinical complexity of the study group, in which various aspects of the health and treatment may influence their quality of life. Among the eight domains of the SF-36, the highest evaluation was for Social aspects and the worse, for Physical aspects, with the other domains having similar means between 60.8 (Pain) and 69.0 (General health status). In a study performed with North American patients, the authors obtained similar results, with regard to the domain with better evaluation (Social aspects) and with the worst evaluation (Physical aspects). However, in other domains, such as Physical 
functioning, Vitality and General health status, the patients presented mean scores below 50, whereas in the present study, the values were above $60^{(12)}$. A study performed with Argentinean patients( ${ }^{(6)}$, although the more compromised domain was Pain, domains such as Physical functioning ( $x=50.0)$, Vitality ( $x=54.4)$ and General health status ( $x=53.7$ ) also had mean values below those found among the subjects of this study.

When comparing the measurements of HRQoL in relation to the age of the participants, statistically significant differences were only found for the domains Physical functioning and Pain. For the Physical functioning domain, the best evaluation was obtained from the subjects under 40 years of age and the worst for those over 60 years. This result confirms that young individuals present better physical functioning, i.e. less physical limitation to carry out activities (vigorous or activities of daily living), when compared to the elderly(6). The domain Pain had the best evaluation among the elderly and the worst among individuals aged between 40 and 59 years. Thus, among the elderly, a lower frequency was found of reports of pain and less interference of the oral anticoagulants in their lives, given that generally they had previously presented other chronic conditions associated with the situation that led to the use of anticoagulants, possibly being just another medication among the various other medications that they need to use chronically.

When comparing the HRQoL measurements according to gender, the men had higher scores than the women, in the majority of the domains of the SF36, except for General health status. However, these differences were only statistically significant in the domains Mental health and Pain. Similar results were found in other studies ${ }^{(6,20,23)}$. It is believed that this could be due to the fact that men give less importance to healthcare, often delegating this responsibility to their wives.

Statistically significant differences were found for the measurements of the domains Physical aspects $(p=0.04)$ and Physical functioning $(p=0.03)$, presented in the three groups of patients classified according to clinical indication of the OAC. In this first domain, the patients with an indication due to the use of metallic prosthetic heart valve had better evaluations than the others. In the second domain, Physical functioning, the subjects with metallic prostheses also presented higher scores, followed by those with other clinical indications. These results were also observed in a previous study(6), in which the authors verified a better evaluation of the HRQOL in individuals with metallic prosthetic heart valves, compared to individuals diagnosed with atrial fibrillation.

HRQoL also differed when the subjects were evaluated according to duration of the use of OAC. A better HRQOL was verified among those in long-term treatment (over 10 years of use) and worse for those with short durations (less than one year). Other patients with less than one year of therapy also presented low SF36 scores $^{(6)}$. These results suggest that the relationship of HRQOL with the duration of OAC use may be related to the period of adaptation and change of habits resulting from the therapy, in the initial months of the treatment. Thus, individuals with longer use could have already adapted, with regard to changing eating habits and behavior, as well as to the dosage and possible collateral effects of the medication.

\section{Conclusion}

The evaluation of health related quality of life in individuals using oral anticoagulants presented a better evaluation for the Social aspects domain and worse for the Physical aspects domain. When compared, according to the sociodemographic and clinical variables, the health related quality of life had a worse evaluation among women, the elderly, those with less than one year of therapy, and those with a diagnosis of atrial fibrillation or other indication for oral anticoagulant use.

Considering the scarcity of studies involving the theme of HRQoL and oral anticoagulation, it is believed that the presented results can guide nursing actions directed toward the group of individuals who present a worse HRQoL evaluation, in that the variables gender, age, indication and duration of use of the OACs present associations with some of the HRQoL domains. Such data may help in the prevention of events that may negatively affect the quality of life of these users, as well as providing a base for the health professionals in the planning of individual care, so that the therapy can be as painless as possible for each patient, as they naturally demand certain precautions concerning the control of blood coagulation. Thus, the development of future studies is proposed, with longitudinal designs and the use of instruments specific to measuring the HRQoL in individuals using OAC in order to obtain strong evidence on which to base the conduct of health professionals in relation to oral anticoagulant users. 


\section{References}

1. Prins $M H$, Marrel A, Carita P, Anderson D, Bousser MG, Crijns $H$, et al. Multinational development of a questionnaire assessing patient satisfaction with anticoagulant treatment: the "Perception of Anticoagulant Treatment Questionnaire" (PACT-QC). Health Qual Life Outcomes. 2009; 7:9.

2. Henn CB, Rabelo ER, Boaz M, Souza EN. Conhecimento dos pacientes sobre anticoagulação oral crônica acompanhados em ambulatório especializado. Rev Gaúcha Enferm. 2008;29(2):207-13.

3. Lavítola PL, Spina GS, Sampaio RO, Tarasoutchi F, Grinberg M. Sangramento durante a anticoagulação oral: alerta sobre um mal maior. Arq. Bras. Cardiol. 2009; 93(2): 174-179.

4. Guyatt GH, Cook DJ, Jaeschke R, Pauker SG, Schünemann $\mathrm{HJ}$. Grades of recommendation for antithrombotic agents: American College of Chest physicians evidence-based clinical practice guidelines (8th edition). Chest, 2008;133 Suppl 6:123S-31S.

5. Lancaster TR, Singer DE, Sheehah MA, Oertel LB, Maraventano SW, Hughes RA, et al. The impact $f$ longterm warfarin therapy on quality of life - evidence from a randomized trial. Arch Intern Med. 1991;151:1944-9.

6. Casais P, Meschengieser SS, Sanchez-Luceros A, Lazzari MA. Patients' regarding oral anticoagulation therapy and its effect on quality of life. Curr Med Res Opin. 2005;21(7):1085-90.

7. McCahon D, Murray ET, Holder RL, Fitzmaurice DA. Does self-management of oral anticoagulation therapy improve quality of life and anxiety? Fam Pract. November 10, 2010; doi:10.1093/fampra/cmq089.

8. Fayers PM, Machin D. Scores and Measurements: Validity, Reliability and Sensitivity. Quality of life. Assessment, Analisis and Interpretation.2a.ed. Chichester, England: John Wiley \& Sons., 2007.

9. Matchar DB, Jacobson AK, Edson RG, Lavori PW, Ansell JE, Ezekowitz MD, et al. The impact of patient self-testing of prothrombin time for managing anticoagulation: rationale and design of VA Cooperative Study \#481-the Home INR Study (THINRS). J Thromb Thrombolysis. 2005;19(3):163-72.

10. Howes CJ, Reid MC, Brandt C, Ruo B, Yerkey MW, Prasad $B$, et al. Exercise tolerance and quality of life in elderly patients with chronic atrial fibrillation. J Cardiovasc Pharmacol Therapeut. 2001;6(1):23-9.
11. Samsa G, Matchar DB, Dolor RJ, Wiklund I, Hedner $E$, Wygant $G$, et al. A new instrument for measuring anticoagulation-related quality of life: development and preliminary validation. Health Qual Life Outcomes. [periódico na Internet]. 2004; [acesso 06 out 2009]. 6(2):22-33. Disponível em: http://www.hqlo.com/ content/7/1/9 Doi: 10.1186/1477-7525-7-9.

12. Carvalho ARS. Qualidade de vida relacionada à saúde e adesão ao tratamento de indivíduos em uso de anticoagulação oral: avaliação dos seis primeiros meses de tratamento [tese de doutorado]. Ribeirão Preto (SP): Escola de Enfermagem de Ribeirão Preto da Universidade de São Paulo; 2010. 119 p.

13. Carvalho ARS, Dantas RAS, Pelegrino FM, Corbi ISA. Adaptação e validação de uma medida de adesão à terapia de anticoagulação oral. Rev. Latino-Am. Enfermagem. maio-junho 2010;18(3):301-8.

14. Wild D, Murray M, Shakespeare A, Reaney M, von Maltzahn R. Patient-reported treatment satisfaction measures for long-term anticoagulant therapy. Expert Rev Pharmacoecon Outcomes Res. 2008;8:291-9.

15. Pelegrino FM. Adaptação cultural e validação do instrumento Duke Anticoagulation Satisfaction Scale (DASS): versão para brasileiros em uso de anticoagulação oral [dissertação de mestrado]. Ribeirão Preto (SP): Escola de Enfermagem de Ribeirão Preto da Universidade de São Paulo; 2009. 168 p.

16. Barcellona D, Contu P, Sorano GG, Pengo V, Marongiu F. The management of oral anticoagulant therapy: the patient's point of view. Thromb Haemost. 2000;83(1):49-53.

17. Ware JE Jr, Sherbourne CD. The MOS 36-item ShortForm Health Survey (SF-36): I. Conceptual framework and item selection. Med. Care. 1992;30(6):473-83.

18. Ciconelli RM. Tradução para o português e validação do questionário genérico de avaliação de qualidade de vida "Medical Outcomes 36 Item Short Form Health Survey-SF-36" [tese de doutorado]. São Paulo (SP): Escola Paulista de Medicina da Universidade Federal de São Paulo; 1997. 143 p.

19. Cabral NL, Volpato D, Ogata TR, Ramirez T, Moro C, Gouveia S. Fibrilação atrial crônica, AVC e anticoagulação: Sub-uso de warfarina? Arq Neuropsiquiatr. 2004; 62(4):1016-21. 
20. Gadisseur APA, Kaptein AA, Breukink-Engbers GM, Van Der Meer FJM, Rosendaal FR. Patient selfmanagement oral anticoagulant care vs. management by specialized anticoagulation clinics: positive effects on quality of life. J Thrombosis Haemostasis. 2004; 2:584-91.

21. Santos FC, Maffei FHA, Carvalho LR, Tomazini-Santos IA, Gianini M, Sobreira ML, et al. Complicações da terapia anticoagulante com varfarina em pacientes com doença vascular periférica: estudo coorte prospectivo. J Vasc Bras. 2006;5(3):194-202.

22. Santana APB. Avaliação de pacientes ambulatoriais em uso de anticoagulantes orais. [dissertação de mestrado], Rio Grande do Sul (RS): Universidade Federal de Santa Maria; 2006. 87 p.

23. Sprangers MAG, Regt EB, Andries F, Van Agt HME, Bijl RV, Boer JB, et al. Which chronic conditions are associated with better or poorer quality of life? J Clin Epidemiol. 2000;53:895-907. 